\title{
Cancer metabolism: current perspectives and future directions
}

\author{
C Muñoz-Pinedo ${ }^{\star, 1}$, N El Mjiyad ${ }^{1}$ and J-E Ricci ${ }^{2,3,4}$
}

Cellular metabolism influences life and death decisions. An emerging theme in cancer biology is that metabolic regulation is intricately linked to cancer progression. In part, this is due to the fact that proliferation is tightly regulated by availability of nutrients. Mitogenic signals promote nutrient uptake and synthesis of DNA, RNA, proteins and lipids. Therefore, it seems straight-forward that oncogenes, that often promote proliferation, also promote metabolic changes. In this review we summarize our current understanding of how 'metabolic transformation' is linked to oncogenic transformation, and why inhibition of metabolism may prove a cancer's 'Achilles' heel'. On one hand, mutation of metabolic enzymes and metabolic stress sensors confers synthetic lethality with inhibitors of metabolism. On the other hand, hyperactivation of oncogenic pathways makes tumors more susceptible to metabolic inhibition. Conversely, an adequate nutrient supply and active metabolism regulates Bcl-2 family proteins and inhibits susceptibility to apoptosis. Here, we provide an overview of the metabolic pathways that represent anti-cancer targets and the cell death pathways engaged by metabolic inhibitors. Additionally, we will detail the similarities between metabolism of cancer cells and metabolism of proliferating cells.

Cell Death and Disease (2012) 3, e248; doi:10.1038/cddis.2011.123; published online 12 January 2012

Subject Category: Cancer

Facts

- Cancer cells proliferate rapidly thanks to metabolic changes.

- Nutrients, particularly glucose and glutamine, are used by cancer cells to produce ATP but also metabolites for growth.

- Oncogenic pathways such as those promoted by Ras, $\mathrm{PI} 3 \mathrm{~K}$ or myc promote glycolysis, while tumor suppressors like p53 inhibit it.

- Oncogenic transformation promotes sensitivity to inhibition of certain metabolic pathways (synthetic lethality).

\section{Open Questions}

- Is there a specific metabolic profile of tumor cells, different to that of non-transformed proliferating cells?

- Which enzymes and metabolic pathways are regulated by specific oncogenes?

- Which nutrients and metabolites are essential for which type of cancer?

- What is the influence of diet on cancer development and treatment?
- Can we develop non-toxic inhibitors of metabolic pathways with clinical efficacy?

All cells in our bodies require oxygen and nutrients. Energy is constantly needed to perform cellular functions, from muscle contraction to neuronal communication. Nutrients, however, are not only required to produce energy. Cells are constantly recycling components such as proteins and membranes and damaged organelles, and they also remodel their components to adapt to new situations, and in this process they may need new building blocks. In the case of cells induced to proliferate, nutrients are needed in abundance for rapid growth. Cancer cells therefore require a plentiful supply of nutrients. It has been known for almost a century that metabolism of cancer cells is 'special' because these cells consume glucose avidly but they only use a small portion for oxidative phosphorylation (respiration) even in the presence of sufficient oxygen. ${ }^{1}$ Instead, cancer cells utilise glycolysis, which yields less ATP and can occur in hypoxic tissues which cannot obtain ATP through respiration. A number of theories have been proposed to explain this phenomenon known as

\footnotetext{
${ }^{1}$ Cell Death Regulation Group, IDIBELL (Bellvitge Biomedical Research Institute), Gran Via de L'Hospitalet 199, L'Hospitalet, Barcelona 08908 Spain; ${ }^{2}$ Inserm, U895, Centre Méditerranéen de Médecine Moléculaire (C3 M), équipe 'controle métabolique des morts cellulaires', Nice, F-06204 Cedex 3, France; ${ }^{3}$ Université de NiceSophia-Antipolis, Faculté de Médecine, Institut Signalisation et Pathologie (IFR50), Nice, France and ${ }^{4}$ Centre Hospitalier Universitaire de Nice, Département d'Anesthésie Réanimation, Nice, France

${ }^{*}$ Corresponding author: C Muñoz-Pinedo, IDIBELL, Gran Via de L'Hospitalet 199, L'Hospitalet (Barcelona) 08908 Spain. Tel: +34 932607339 ;

Fax: + 3493260 7426; E-mail: cmunoz@idibell.cat

Keywords: cancer; cell metabolism; glucose; oncogenes

Abbreviations: ACL, ATP cytrate lyase; AMPK, AMP-activated protein kinase; FAS, fatty acid synthase; HIF, Hypoxia-Inducible Factor; IDH1 and IDH2, isocitrate dehydrogenases 1 and 2; IGF-1, insulin-like growth factor 1; MAGL, monoacylglycerol lipase; mTOR, mammalian Target of Rapamycin kinase; PDK1, Pyruvate Dehydrogenase Kinase 1; PKM2, pyruvate kinase M2 isoform; PI3K, Phosphatidylinositol 3-kinase; ROS, reactive oxygen species; SREBP, Sterol Regulatory ElementBinding Protein; TCA cycle, tricarboxylic acid cycle (Krebs cycle)

Received 29.7.11; revised 19.9.11; accepted 27.9.11; Edited by G Melino
} 
'the Warburg effect'. Amongst them, adaptation to tumor hypoxia and inability to respire due to mitochondrial mutations could be responsible for the shift to a glycolytic phenotype. However, work in recent years has revealed that the glycolytic switch is promoted by oncogenes and inhibited by tumor suppressors, indicating that it is intrinsically associated with oncogenic transformation. ${ }^{2,3}$ Indeed, metabolic reprogramming is not only associated with oncogenic mutations, but also with proliferation of non-transformed tissues. The glycolytic switch and other metabolic changes also occur in normal cells induced to proliferate such as activated T lymphocytes. From this, numerous questions arise: is there a general metabolic profile of tumor cells which is different from metabolism of noncancerous but proliferating tissues? Can we exploit the metabolic particularities of cancer cells without affecting normal tissues? We will discuss the metabolic reprogramming linked to proliferation, how oncogenic transformation drives this reprogramming, and some features of cancer metabolism that can be targeted.

\section{Cell Proliferation and Oncogenesis are Coupled to Metabolic Reprogramming}

Proliferating cells have an increased uptake of glucose and glutamine. Glucose is frequently metabolized through glycolysis. Pyruvate, its product, enters the Krebs cycle or is excreted as lactate. This step, conversion of pyruvate to lactate is required to regenerate $\mathrm{NAD}^{+}$for glycolysis, and is linked to oncogenesis as we will discuss later (Figure 1). Glucose, together with amino acids, is also used to produce nucleic acids through the pentose phosphate pathway. Glycolytic intermediates are utilized by growing cells to

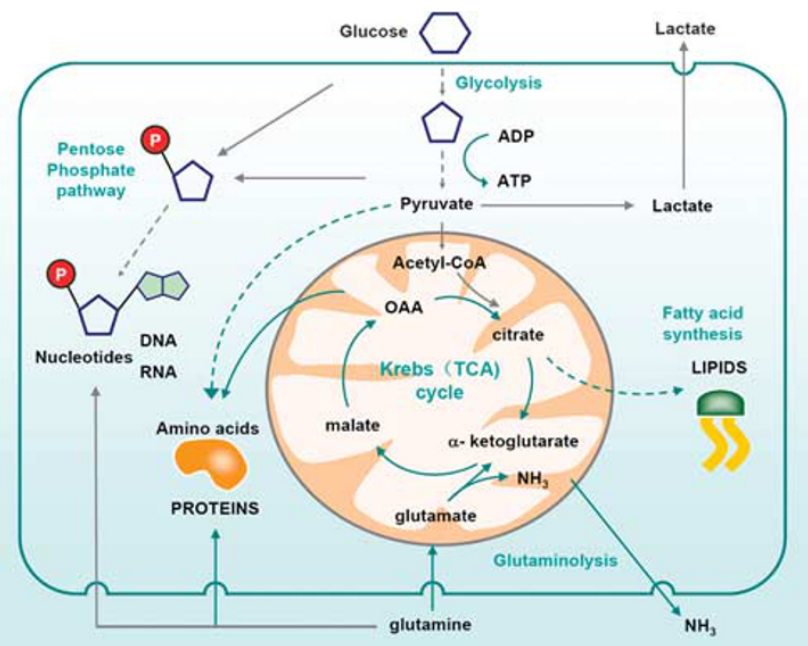

Figure 1 Metabolism of proliferating cells. Proliferating cells require glucose which is converted to pyruvate through glycolysis. Pyruvate is converted to acetyl$\mathrm{CoA}$ which enters the Krebs (TCA) cycle in the form of citrate. Alternatively, citrate is exported back to the cytosol to be used for lipid synthesis. Glucose can be also used as a source of carbon to produce ribose through the pentose phosphate pathway. Ribose-5-phosphate is then used to make RNA and DNA. Moreover, glycolytic intermediates such as pyruvate are used to produce non-essential amino acids such as alanine. Cells also require amino acids such as glutamine to make other amino acids and proteins. 'Waste' is secreted in the form of lactate (mostly from glycolysis) and ammonia (from catabolism to amino acids) produce fatty acids and non-essential amino acids. Increased glycolysis and lipid biosynthesis are characteristics common to all highly proliferative cells, including activated T-cells during acute stimulation and cells exposed to growth factors. $^{4,5}$ Indeed, like cancer cells, these cells need to support high proliferation rates and thus require efficient biosynthesis of macromolecules. Consequently, signals leading to increased proliferation must also drive the necessary adaptation to the new metabolic needs.

Growth factors activate Ras to transduce proliferation signals. Not surprisingly, this protein is very often mutated leading to its hyperactivation in cancer. Ras mediates the activation of several effector pathways like PI3K/Akt and MAPK pathways. ${ }^{6-8}$ The PI3K/Akt pathway, which is also activated by growth factors, leads to increased glycolysis through several ways. Akt promotes the increased expression and membrane localization of the glucose transporter GLUT1, it stimulates phosphofructokinase activity and the association of hexokinases 1 and 2 with the mitochondria. ${ }^{9-12}$ Downstream of Akt, mammalian Target of Rapamycin kinase (mTOR) stimulates numerous metabolic pathways. ${ }^{13} \mathrm{PI} 3 \mathrm{~K} /$ Akt/mTOR and MAPK pathways are involved in lipid biosynthesis (Figure 2), notably through the SREBP dependent transcription of several key enzymes such as ACL (ATP citrate lyase) and FAS (fatty acid synthase). ${ }^{14,15}$

MYC is activated by growth factors and it regulates the transcription of thousands of genes or microRNAs involved in cellular proliferation. Myc overexpression has been described

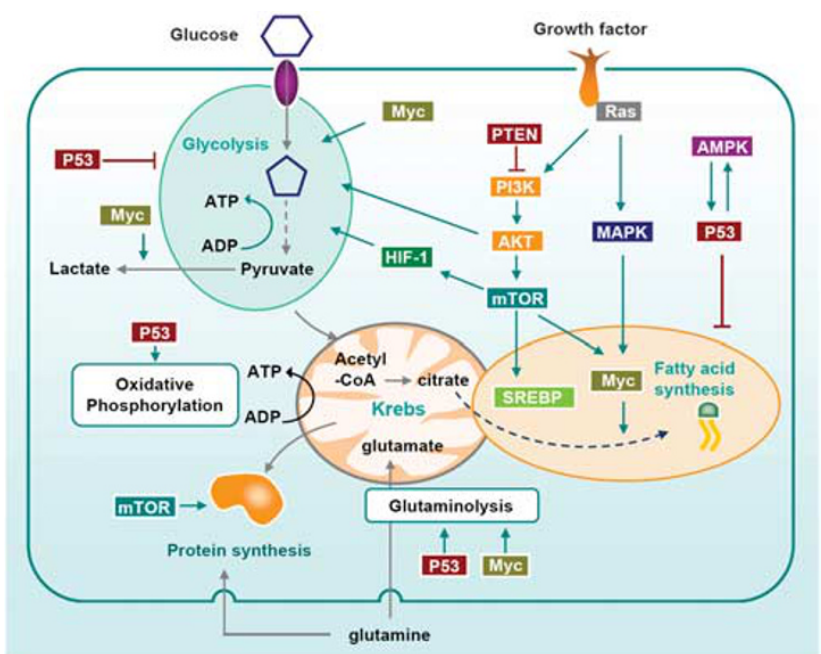

Figure 2 Signaling pathways that regulate metabolism of proliferating and cancer cells. Growth factors influence metabolism through Ras and PI3K. Both PI3K/Akt and MAPK increase glycolysis. They also induce the upregulation of the transcription factor SREBP which promotes lipogenesis. mTOR, downstream of $\mathrm{PI} 3 \mathrm{~K} / \mathrm{Akt}$ also plays a central role in the metabolic switch observed in highly proliferating cells: it activates protein translation, glycolysis (through HIF-1 dependent and independent pathways) and lipogenesis through the transcription factors SREBP and Myc. Myc is also the main oncogene implicated in glutamine addiction of cancer cells, through the upregulation of glutamate synthesis. It also contributes to the Warburg effect by increasing glycolysis and lactate production. AMPK activation, which is often impaired in tumors, allows the cells to switch their metabolism to catabolism when the nutrients are scarce. p53 regulates metabolism at multiple steps, notably through the upregulation of glutamate synthesis and inhibition of fatty acid synthesis and glycolysis ${ }^{40,119}$ 


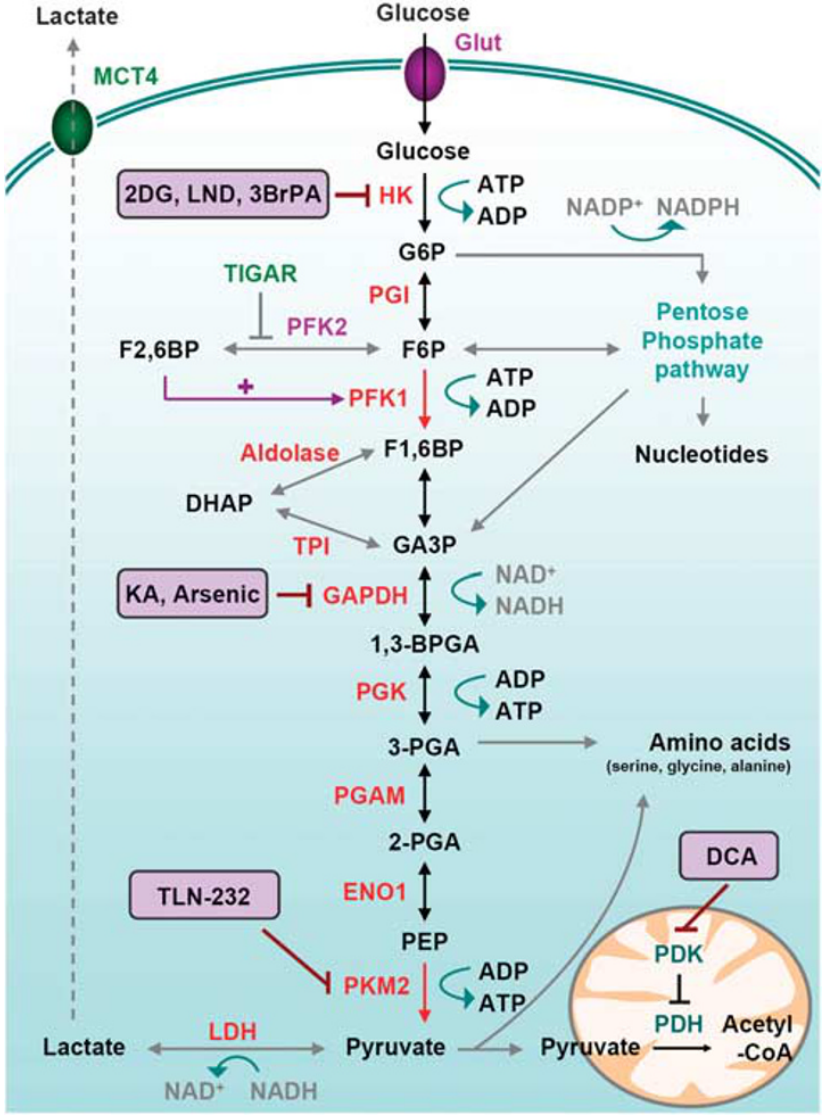

Figure 3 Glucose metabolism in cancer cells. Glycolysis is a series of metabolic processes, driven by nine specific enzymes, by which one mole of glucose is catabolized to two moles of pyruvate, two moles of NADH with a net gain of two ATP. As indicated, several intermediates can fuel the Pentose Phosphate Pathway or lead to amino acid production. Accumulation of those intermediates is favored by the ratelimiting activity of PKM2. In cancer cells, pyruvate is further converted into lactate, thereby generating $N A D^{+}$from NADH. Pyruvate can be imported in the mitochondrial matrix to feed the TCA cycle. This step is controlled by Pyruvate Dehydrogenase Kinase (PDK) which can inactivate Pyruvate Dehydrogenase (PDH), therefore limiting the pyruvate conversion into acetyl-COA and the further feeding of the TCA cycle.

- Transporters: Glut: Glucose transporter; MCT: monocarboxylate transporter.

- Glycolytic intermediates: G6P: Glucose-6-phosphate, F6P: fructose-6-phosphate; F1,6BP: fructose-1,6-bisphosphate; F2,6BP: fructose-2,6-bisphosphate; DHAP: dihydroxyacetone phosphate; GA3P: Glyceraldehyde-3-phosphate; 1,3-BPG: 1,3-bisphosphoglycerate; 3-PGA: 3-phosphoglycerate; 2-PG: 2-phosphoglycerate; PEP: phosphoenolpyruvate;

- Enzymes: HK: hexokinase; PGl: phosphoglucoisomerase; PFK: Phosphofructokinase; TPI: triose phosphate isomerase; GAPDH: Glyceraldehyde 3-phosphate dehydrogenase; PGK: phosphoglycerate kinase; PGAM: phosphoglycerate mutase; ENO1: enolase 1; PK: pyruvate kinase; LDH: lactate dehydrogenase.

- Chemical inhibitors are indicated in bold; 2DG: 2-Deoxy-Glucose; LND: Lonidamine; 3BrPA: 3-Bromopyruvate, KA: Koningic Acid; TLN-232 is a synthetic cyclic heptapeptide which targets PK; DCA: Dichloroacetate

in many types of cancer. Myc has been shown to regulate glutamine uptake and utilization in several ways. ${ }^{16}$ For instance, through the repression of miR-23a and miR-23b, which leads to the induction of their target enzyme mitochondrial glutaminase $1 .^{17}$ This enzyme initiates mitochondrial catabolism of glutamine to enter the Krebs cycle. On the other hand, Myc promotes aerobic glycolysis by enhancing the expression of GLUT1 and also of lactate dehydrogenase A, which converts pyruvate to lactate and thereby contributes to the Warburg effect. ${ }^{18}$ Very recently, using a very powerful spectrometric imaging system, $\mathrm{Hu}$ et al observed metabolic changes in a model of c-myc driven oncogenesis and they established that those metabolic changes preceded tumor formation and were modulated by inactivation of c-myc. ${ }^{19}$ This work identified modifications of glycolysis and alanine synthesis pathways in pre-tumor stages. Alanine is synthesized from pyruvate, and it is not the only amino acid synthesized from glucose; serine and glycine are also synthesized from glycolytic intermediates (Figure 3). This highlights the relevance of glucose metabolism not only as a source of ATP but also as a source of biosynthetic precursors for cancer cells.

\section{Regulation of Glycolysis by PKM2}

The high proliferating rate of cancer cells forces them to produce more energy but also more macromolecules. Pyruvate kinase (PK) seems to play a key role in this context. It is the final enzyme of the glycolytic pathway converting phosphoenolpyruvate into pyruvate with the production of ATP (Figure 3). There are 4 forms of PK (L, R, M1 and M2) derived from 2 distinct genes. PKM1 and PKM2 originate from the same gene submitted to alternative splicing. The alternative splicing in favor of PKM2 was shown to be mediated by three heterogeneous nuclear ribonucleoproteins, hnRNP1, hnRNPA1 and hnRNPA2, under the regulation of the oncogene c-myc. ${ }^{20} \mathrm{PKs}$ are among the most regulated enzymes of the glycolytic pathway. ${ }^{21} \mathrm{PKM} 2$ is of particular interest in the context of cancer as it is the predominant form of PK in those cells. Whereas PKM1 is constitutively active with a rapid substrate turnover, $\mathrm{PKM} 2$ can switch from high to lowactivity states depending on the cellular needs. In this sense, pro-mitogenic signals, such as binding with phosphotyrosine or phosphorylation by FGFR1, have been suggested to promote cell and tumor growth by decreasing PKM2 activity. ${ }^{22-24}$ In a counter-intuitive manner, this isoform of PK which promotes glycolysis and the Warburg effect is less efficient than PKM1. Low activity of PKM2 is useful for cancer cells because it promotes the use of glycolytic intermediates for biosynthetic pathways. mTOR upregulates PKM2, and this effect was described as mediated though Hypoxia-Inducible Factor (HIF)-1 $\alpha$, a transcription factor that reprograms cancer cell metabolism, as we will discuss later. ${ }^{25}$ Conversely, PKM2 was shown to promote transcriptional activity of HIF-1 through direct binding. ${ }^{26}$ Altogether, this suggests that the paradoxical low pro-glycolytic activity of PKM2 could be compensated by an increase in HIF-1 transcriptional activity, what would promote glycolysis at several levels.

Recently, a very exciting report established another reason why cancer cells would benefit from the expression of a less efficient PK isoform. ${ }^{27}$ As mentioned above, by expressing PKM2, cancer cells will accumulate several intermediates, including phosphoenolpyruvate (PEP), the substrate for pyruvate kinase in cells (Figure 3 ). The authors showed that a phosphate group from PEP was transferred to the glycolytic protein phosphoglycerate mutase 1 (PGAM1) what would therefore increase its mutase activity. This provided an efficient mean to produce pyruvate in a PK-independent 
manner. One probable main advantage for cancer cells to use this PK-independent pathway is the failure to generate ATP by PK, because ATP can itself inhibit upstreams steps in glycolysis. Therefore, cancer cells, by using a less efficient PK isoform, will activate this alternative pathway allowing the dissociation between ATP production and the anabolic processes that are required for fast cancer cell division.

\section{Hypoxia and Cancer Metabolism}

Variation of oxygen content is frequently observed in normal tissues as in tumors. However, in tumors, the gradient is much steeper as $\mathrm{O}_{2}$ concentrations can drop to near zero in necrotic core areas. One main mechanism allowing cells to adapt to hypoxia is mediated through the stabilization of the transcription factor HIF-1. Within any given cell type, HIF-1 controls the expression of hundreds of genes including several glycolytic enzymes, glucose transporters, Lactate dehydrogenase A and others. ${ }^{28,29}$ In conditions where HIF-1 $\alpha$ is stabilized (hypoxic conditions but also following inactivating mutations in tumor suppressor proteins) the capacity of tumor cells to carry out glycolysis is increased. In addition, HIF-1 will activate Pyruvate Dehydrogenase Kinase 1 (PDK1), a negative regulator of the mitochondrial pyruvate dehydrogenase complex and thereby reduce the flow of pyruvate used by the TCA cycle (Figure 3). Recently, dichloroacetate (DCA), a PDK inhibitor, was administrated to five patients suffering from glioblastoma, a very aggressive primary brain tumor with limited therapeutic options. ${ }^{30}$ This study established that DCA was tolerated and also indicated that it could improve the therapeutic response of patients. However, it is important to note that a couple of relatively old studies reported nerve toxicity of this drug suggesting that its use will probably have to be restricted to selected patients. ${ }^{31,32}$

\section{Promoting Chemical Synthetic Lethality by Modulating Cancer Metabolism}

As discussed earlier, cancer cells use the same pathways than proliferating cells to reprogram their metabolism and stimulate proliferation (for reviews about regulation of metabolism by oncogenes see Caims et al..$^{33}$ and Kroemer et $a l^{34}$ ). There is a chance that metabolic targeting will thus pose the same problems than conventional chemotherapy, that is, that normal proliferative tissues will be affected. However, our hopes lie in two aspects of cancer biology: (1) the nutrient poor, hypoxic metabolic milieu that cancer cells live in may make them more susceptible to metabolic targeting, and (2) hyperactivation or inactivation of pathways such as mTOR and p53 will make tumors particularly sensitive to these therapies. Synthetic lethality arises when simultaneous mutation of two genes is lethal, while mutation of each one alone is not (Figure 4). Chemical synthetic lethality is obtained when inhibition of a gene product is lethal to cells which present other mutations. Metabolic inhibition has been shown to be synthetically lethal to cancer cells because hyperactivation or oncogenes tends to make them 'addicted' to glucose or glutamine, but also because energetic stress engages a 'metabolic checkpoint' which cannot occur in cancer cells with certain mutations such as deficiency in p53.

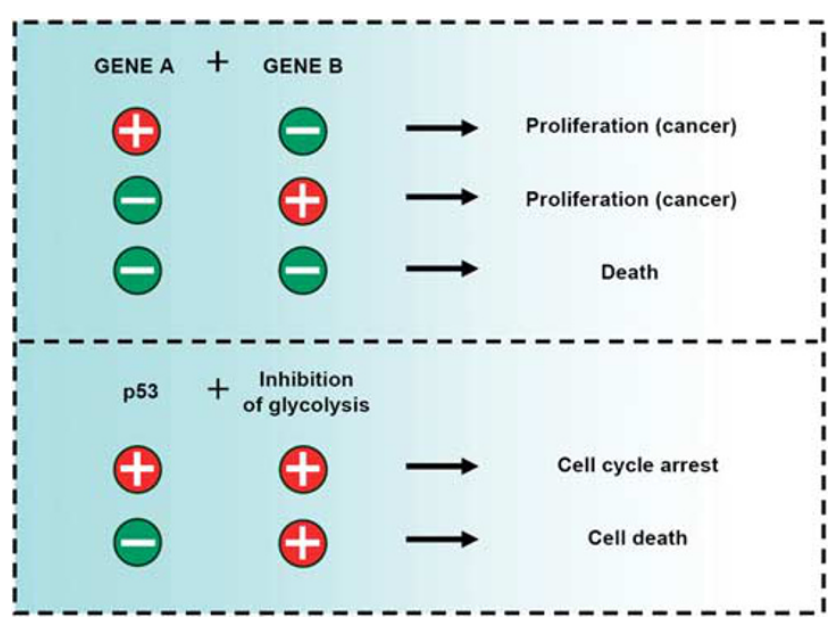

Figure 4 Metabolic synthetic lethality. Synthetic lethality in organisms occurs when the simultaneous mutation of two genes is lethal, while mutation in each individual gene is not. Mutations in certain genes that occur frequently in cancer (for instance, p53) promote sensitivity to inhibition of specific metabolic pathways, which can be exploited to selectively target tumors with those mutations

\section{Metabolic Checkpoint: p53, mTOR, AMPK}

The p53 protein is coded by the TP53 gene, which is the most frequently mutated gene in human tumours and functions as the 'guardian of the genome'. ${ }^{35}$ p53 acts as a tetrameric transcription factor that induces hundreds of target genes involved in regulation of apoptosis, cell cycle and DNA repair among others. ${ }^{36}$ Loss of p53 promotes glycolysis (Figure 2). p53 inactivation can lead to the Warburg effect by several means, including the transcriptional regulation of TIGAR (TP53-induced glycolysis and apoptosis regulator, a fructose-2,6-bisphosphatase) ${ }^{37}$ or the synthesis of the protein $\mathrm{SCO} 2$ which is required for the correct assembly of the cytochrome $c$ oxidase (COX) complex of the electron transport chain. ${ }^{38}$ In addition, p53, like myc, promotes glutamine utilization (Figure 2) by upregulating glutaminase 2; this is thought to participate in antioxidant responses mediated by $\mathrm{p} 53$, because glutamine is required for glutathione synthesis. ${ }^{39,40}$ On the other hand, p53 is activated when cells undergo metabolic or hypoxic stress. ${ }^{35,41}$ Cells that lack p53 -like many tumor cells- cannot undergo a metabolic checkpoint when glucose is scarce and they die. ${ }^{42}$ Another protein that participates in this checkpoint upstream of $p 53$ is the ATP sensor AMPK (AMP-activated protein kinase). This protein promotes cell survival in the face of metabolic stress by promoting cell cycle arrest, by downregulating anabolic pathways and by promoting catabolism. On the other hand, the AMPK activator LKB1 is absent in many tumors, which makes these cells more sensitive to nutrient deprivation because they cannot react and adapt to metabolic stress. ${ }^{43}$ AMPK also participates in inactivation of mTOR, which is a master regulator of protein translation and proliferation. This protein, and the mTORC1 complex in which it is activated, sense the nutritional status of the cells. If nutrients are absent, cells do not synthesize proteins and they stop growing. But when mTOR is hyperactivated, such as in an oncogenic context by mutation of the tumor suppressor TSC, cells become susceptible to glucose deprivation. These cells keep 
trying to use nutrients for anabolic pathways because they cannot match nutrient supply and demand. This causes mTOR-mediated energetic stress and cell death. ${ }^{44}$ This indicates that loss of TSC, like loss of p53, promotes synthetic lethality with blockade of glycolysis.

We have discussed above examples of signaling pathways that promote synthetic lethality with metabolic inhibitors. But importantly, metabolic enzymes themselves have also been found altered in cancer. Some examples are isocitrate dehydrogenases and phosphoglycerate dehydrogenase, which will be discussed later. Fumarate hydratase $(\mathrm{FH})$, an enzyme of the TCA cycle is mutated in some tumors. Its absence has recently been found to promote susceptibility to inhibition of haem oxygenation, providing another example of synthetic lethality. ${ }^{45}$

\section{Lactate}

Lactate synthesis pathways, or $\mathrm{pH}$ changes associated with lactic acid production are also susceptible to be targeted to promote synthetic lethality. As we have discussed, transformed cells convert a good proportion of incoming glucose to lactate instead of metabolizing it through oxidative phosphorylation, therefore creating an acidic microenvironment. The local modification of the microenvironment is supposed to bring several advantages to the tumors: favoring invasion ${ }^{46}$ and suppressing anticancer immune effectors. ${ }^{47}$ Indeed, lactate was reported as able to suppress the proliferation, cytokine production and the cytolytic activity of cytotoxic $T$ lymphocytes (CTLs). However, it should be investigated more thoroughly whether lactate production under aerobic conditions is truly a selective feature of cancer cells and not of other highly proliferating tissues.

\section{Isocitrate Dehydrogenases (IDH1/2) and Oncometabolite Production}

Mutations in isocitrate dehydrogenases (IDH1 and IDH2) genes have been linked to tumorogenesis. ${ }^{48,49} \mathrm{IDH} 1$ and IDH2 are homodimeric enzymes that act in the cytoplasm and in mitochondria respectively, to control one of the irreversible steps in the TCA cycle essential for cellular respiration. Those enzymes will convert isocitrate into $\alpha$-ketoglutarate $(\alpha-K G)$ generating carbon dioxide, $\mathrm{NADH}$ and $\mathrm{NADPH}$ as side products. Their roles in cell growth are not interchangeable. However, once mutated (on Arg132 for IDH1 and Arg140 and 172 for IDH2) both enzymes will further metabolize $\alpha-\mathrm{KG}$ into 2-hydroxy-glutarate (2-HG), which is regarded as an 'oncometabolite'. Interestingly, in glioma and Acute Myeloid Leukemia (AML) patients with IDH1/2 mutations, this metabolite was found increased by 100 -fold, suggesting that it could be used as a clinical biomarker. ${ }^{50,51}$ The function of 2-HG remains poorly understood but it is fascinating to note that almost every IDH1 and IDH2 mutations were associated with specific methylation profiles suggesting epigenetic control. This is most likely promoted by the fact that the lower level of $\alpha-K G$ and the accumulation of the antagonist (2-HG) will prevent the activity of histone demethylases (enzymes involved in epigenetic control). ${ }^{52}$ In addition, as $2-\mathrm{HG}$ is an analogue of $\alpha-K G$ it will inhibit TET2, an enzyme catalyzing the conversion of methylcytosine $(5 \mathrm{mC})$ to 5-hydroxymethylcytosine $(\mathrm{hmC})$. The exact function of $\mathrm{hmC}$ is still unknown but it may influence chromatin structure and seems to ultimately lead to base-excision repair and de novo production of un-methylated cytosine. ${ }^{53}$ It was also reported that overexpression of IDH1 Arg132 mutants results in elevated $\mathrm{HIF}-1 \alpha$ levels through an increase in $2-\mathrm{HG}$ production. $^{54}$ However a recent study indicated that an upregulation of HIF by $2 \mathrm{HG}$ is unlikely to be the major factor in IDH mutation-associated oncogenesis. ${ }^{55}$ Even though IDH1 and IDH2 were not the first metabolic enzymes to be involved in oncogenesis, they were the first to link metabolite production to oncogenesis ${ }^{56}$ with major implications in basic cancer biology (adding those enzymes to the list of cancer genes) as in clinical considerations (such as diagnosis).

\section{Active Metabolism Inhibits Cell Death}

Glycolytic metabolism promotes proliferation of cancer cells, but it also protects them from cell death. An increased glycolytic rate renders cancer cells more resistant to apoptosis induced by growth factor withdrawal. For example, it was shown in leukemic cells that overexpression of hexokinase 1 and GLUT1 was sufficient for Akt to protect against IL-3 withdrawal. ${ }^{11}$ Under normal glucose conditions, IL-3 withdrawal targets the antiapoptotic protein Mcl-1 for proteasome degradation leading to cell death. ${ }^{57}$ However, when glucose levels are high, Mcl-1 is more stable ${ }^{58}$ (Figure 5). Furthermore, if glycolysis is inhibited, the AMPK/ mTOR axis inhibits translation of $\mathrm{Mcl}-1$, making cells more susceptible to death ligands. ${ }^{59}$ Inhibition of translation of Mcl-1 through inhibition of metabolism may also represent a new strategy to sensitize cells to $\mathrm{BH} 3$ mimetics (personal data and Coloff et al. $^{60}$ ). These drugs are inhibitors of the antiapoptotic proteins $\mathrm{Bcl}-2$ and $\mathrm{Bcl}-\mathrm{xL}$ which are attracting attention as novel cancer therapeutics. ${ }^{61-63}$

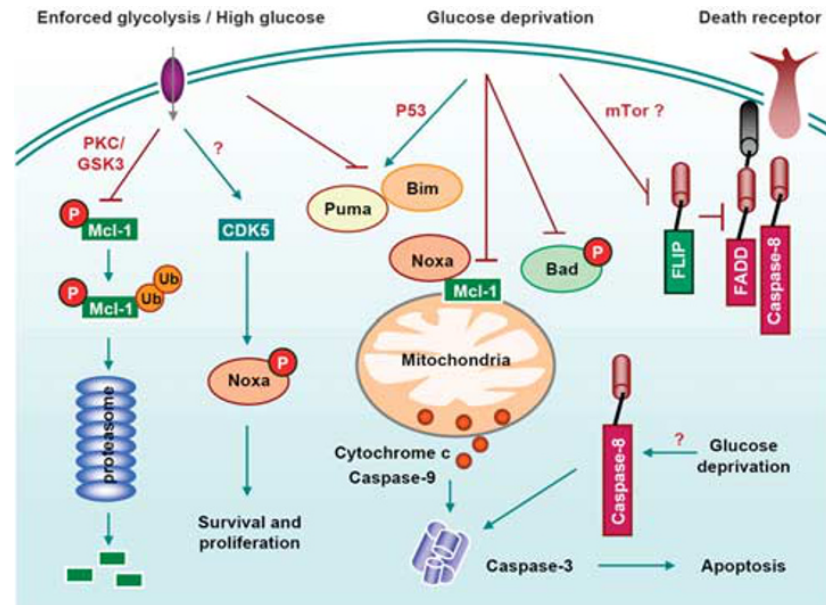

Figure 5 Regulation of cell death by glucose metabolism. Nutrient availability regulates cell death induced by death receptors and by stimuli that kill through the mitochondrial pathway by regulating the antiapoptotic $\mathrm{Bcl}-2$ family member Mcl-1, pro-apoptotic BH3-only proteins (Puma, Bim, Noxa and Bad) and c-FLIP. ${ }^{64}$ Glucose deprivation induces necrosis (not shown), caspase-8 mediated -but death receptor independent- apoptosis ${ }^{120}$ or mitochondrial apoptosis mediated by Noxa, Puma, Bad or Bim ${ }^{41}$ 
An increased glycolytic metabolism also inhibits expression or activity of several pro-apoptotic $\mathrm{BH}$-only proteins, which mediate death induced by physiological agents and chemotherapeutic drugs ${ }^{64}$ (Figure 5). For instance, overexpression of GLUT1 was shown to inhibit p53 and Puma induction upon growth factor withdrawal. ${ }^{41}$ Moreover, hexokinase1/ GLUT1 overexpression inhibited sensitivity of cells to transfection of DNA encoding for Bim. ${ }^{58}$ Metabolic stress has been shown to regulate $\mathrm{BH}$-only proteins. For instance, high glucose levels promote CDK5-mediated phosphorylation and inactivation of Noxa in leukemic cells. ${ }^{65}$ Additionally, under low glucose conditions, Bad is dephosphorylated and it induces apoptosis. ${ }^{66}$

Besides the mitochondrial apoptotic pathway, it was shown in several cancer cell lines that glucose deprivation induced a drop in cFLIP levels and sensitization to death receptors. ${ }^{67}$ Moreover, it was shown that maintenance of ATP production through keeping mitochondria active, or overexpression of the glycolytic enzyme GAPDH promotes survival of cancer cells even when they have undergone mitochondrial permeabilization during apoptosis. ${ }^{68-70}$ Thus, cancer cells may benefit from keeping an active metabolism not only because it is required by proliferation, but also because it helps to escape cell death.

\section{Killing Cancer Cells by Inhibiting Glucose Metabolism}

Most tumors are highly dependent on glucose. Over the years, chemists have developed inhibitors against almost every step of glycolysis that are being extensively tested in vitro, in vivo and in clinical trials (Figure 3). ${ }^{71,72}$ Targeting glucose metabolism with agents such as 2-deoxyglucose may be toxic at doses required to achieve tumor regression, although this may depend on the type of tumor examined. Besides a possible use as monotherapy, inhibitors of glucose metabolism can enhance the efficacy of chemo- and radiotherapy (for an extensive review on the subject see Mijiyad et al. ${ }^{64}$ ). Some of these drugs are inexpensive, and combinations with chemotherapy may be worth exploring in the clinic.

As discussed above, once pyruvate is produced, it can be transformed into lactate to regenerate NAD for glycolysis (Figures 1 and 3) or enter the mitochondria and support the Krebs cycle. Lactate production and extrusion as well as $\mathrm{pH}$ regulating systems could potentially be targeted to kill or slow down proliferation of cancer cells, ${ }^{73}$ although this could also be potentially toxic for muscle. An interesting approach discussed earlier is to promote the use of pyruvate in the Krebs cycle and thus reduce lactate production (Figure 3).

Factors that promote resistance to glycolysis inhibitors include apoptotic proteins. It is thus relevant to understand the mechanism of cell death induced by these drugs. Glucose deprivation induces apoptosis or necrosis depending on the cell type, and it is not understood what accounts for the difference in response (for a review see Caro-Maldonado et al. $\left.^{74}\right)$. Moreover, the apoptotic mediators seem to be different depending on the cell type. Additionally, the machinery of cell death engaged by glucose deprivation or by glucose analogs can be different in the same cells
(Ramirez-Peinado et al. ${ }^{75}$ and our unpublished observations). It would be relevant to understand if some specific proteins mediate cell death of tumor but not non-transformed cells.

\section{Targeting Amino Acid Metabolism}

The capacity of cancer cell to use glucose in support of bioenergetic and macromolecular synthesis is not the only particularity of cancer cell metabolism. In fact in the mid-20th century Eagle observed that many cancer cells lines cannot survive in absence of exogenous glutamine, therefore suggesting the 'glutamine addiction' of some cancer cells. ${ }^{76}$ It seems that glutamine, even if considered as a non-essential amino acid that can be synthesized from glucose, is the nitrogen donor for several key metabolic enzymes and for the de novo synthesis of both purines and pyrimidines and it appears to be required for anabolic growth of mammalian cells notably through its ability to control the master regulator of protein translation $\mathrm{mTORC} 1 .{ }^{77}$ Finally, glutamine is also a key mitochondrial substrate required for maintenance of TCA cycle and mitochondrial membrane potential. ${ }^{78}$ For all those reasons, several approaches were launched to target glutamine addiction of those cancer cells (reviewed in Wise and Thompson ${ }^{79}$ ). One of these approaches is the use of L-asparaginase, an asparagine-depleting enzyme which has shown promising results for the treatment of pediatric acute lymphoblastic leukemia (ALL). ${ }^{80}$ This enzyme also depletes glutamine, what correlates with its anti-tumor activity better than its ability to deplete asparagine. Unfortunately, in adults, L-Asparaginase has shown significant toxicity. ${ }^{81}$

Recently, using in vivo negative-selection RNAi screens, Possemato et al. established that another amino acid biosynthesis pathway, the serine pathway, is essential to most estrogen negative breast cancers subtypes. ${ }^{82}$ In the same line, Vander-Heiden and colleagues showed that phosphoglycerate dehydrogenase $(\mathrm{PHGDH})$ which is found overexpressed in some tumors, can divert glucose-derived carbon into serine and glycine metabolism and that this change can be selected for during the development of human cancer. $^{83}$ These studies suggest that targeting this pathway, at least in breast cancers presenting a high expression of phosphoglycerate dehydrogenase, could represent an innovative treatment modality. The apoptotic pathways engaged by amino acid shortage have not been thoroughly explored, but some reports indicate that cell death occurs via mitochondrial apoptosis, possibly mediated by the Noxa/ Mcl-1 axis. $^{84,85}$

\section{Targeting Lipid Metabolism}

One additional feature of cancer cells is an increased rate of lipogenesis. The newly synthesized lipids will be used for the synthesis of membranes, notably lipid raft and lipid-modified signaling molecules. ${ }^{86}$ Lipid metabolism is increasingly seen as potential target for anti-tumor therapy. Recently, a study compared non tumoral cells with their Src or hRAS transformed counterparts in order to identify a cancer cell signature. This signature shows several common genes with metabolic disorders, inflammation and immune responses. 
They identified several genes such as OLR1, SREBP-1, SNAP23 and VAMP4, which are involved in lipid metabolism, cholesterol biosynthesis, and atherosclerosis. ${ }^{87}$ One molecule that has been driving increased interest recently is SREBP (Sterol Regulatory Element-Binding Protein). This transcription factor, which is a direct target of PI3K/Akt and MAPK pathways, regulates lipid synthesis and uptake through upregulation of key enzymes of lipogenesis. ${ }^{14,15}$ A specific inhibitor of SREBP maturation, Betulin, induces cytotoxicity of cancer cells. ${ }^{88}$

Several enzymes implicated in lipogenesis have been studied as potential target in anti-neoplastic therapy, like fatty acid synthase (FAS), acetyl-CoA carboxylase (ACC) or ATP citrate lyase $(A C L)$. Their down regulation by siRNA expression or chemical inhibition leads to reduced proliferation of the tumors. ${ }^{89} \mathrm{ACL}$ is responsible for the synthesis of acetyl coA from citrate, and its inhibition leads both to the inhibition of cholesterol synthesis and the inhibition of fatty acid synthesis upstream of FAS. It thus appears as a key enzyme to target. Indeed, the use of its chemical inhibitor SB-204990 reduced cell growth and proliferation. ${ }^{90}$ Recently, carnitine palmitoyltransferase $1 \mathrm{C}$ was shown to also be upregulated in cancer cells, leading to increased fatty acid oxidation, ATP production and resistance to hypoxia and glucose deprivation. ${ }^{91}$ Statins are inhibitors of cholesterol synthesis but also of the production of molecules such as isoprenoids. These are lipid anchors for a range of signaling proteins such as the small GTPases Ras and Rho. Statins are commonly used to treat cardio-vascular diseases. Interestingly, epidemiologic studies indicate that their use reduces the incidence of some cancers, and moreover, they can improve efficacy of chemotherapy. ${ }^{92,93}$ However, their efficiency in anti-cancer therapy remains to be studied thoroughly.

\section{Targeting Nucleotide Metabolism}

A group of compounds classically named 'antimetabolites' have been used for decades to treat cancer. These compounds inhibit RNA and DNA synthesis. The widely used drug 5-fluorouracil (5-FU) exerts its toxic effects, in part, by getting misincorporated into RNA. Additionally, its product 5-fluorodeoxiuridine impairs DNA synthesis by blocking thymidylate synthase. This enzyme is responsible for the synthesis of deoxythymidine-triphosphate (dTTP). Thymidylate synthase is also the indirect target of methotrexate and other, newer, anti-folate drugs. By inhibiting the synthesis of dTTP these drugs impair DNA synthesis and promote DNA damage. Since this pathway is more active in proliferating cells than in normal cells, antimetabolites/nucleotide synthesis inhibitors are effective against tumors. ${ }^{94,95}$ Unfortunately, like other metabolic inhibitors and chemotherapeutic drugs they are also quite effective in killing hematopoietic cells and other rapidly dividing cells.

Inhibition of nucleic acid synthesis can also occur as a consequence of targeting other metabolic pathways. Nucleotides are made de novo from amino acids and sugars (Figure 1). The pentose phosphate pathway is required for synthesis of nucleic acids, which means that drugs targeting glucose uptake would also have an effect on RNA and DNA synthesis. Additionally, depletion of selective amino acids such as glutamine would also impair nucleotide synthesis.

\section{Diet and Cancer}

Diet has often been linked to longevity: reducing the calorie intake can influence aging. The mechanism is being actively researched, and it is thought to involve the inhibition of mTOR and the activation of sirtuins. ${ }^{96,97}$ In addition, diet is thought to be a major contributory factor in the development and progression of cancer. Epidemiological studies have highlighted that the population having low sugar, low fat culinary traditions present lower incidence of cancer. ${ }^{98}$ Furthermore, studies in mice have showed that feeding the animal a low carbohydrate, high protein diet, not only decreased cancer development but also reduced tumor growth. ${ }^{99}$ Links between diabetes and cancer have also been established. For instance, it has long been observed that diabetic patients exposed to metformin, a drug that reduces insulin tolerance, have a decreased risk of cancer incidence. ${ }^{100,101}$ Moreover, metformin and other anti-diabetic drugs have been shown to inhibit transformation. ${ }^{87}$ It remains to be determined whether these drugs act indirectly by regulating hormones, through an effect of glucose availability on cancer cells or by directly promoting cell death; metformin, for instance, inhibits mTOR and promotes apoptotic cell death of cancer cells. ${ }^{102}$

High-fat diets have been associated with cancer, and in particular, prostate cancer. ${ }^{103}$ An interesting study on the monoacylglycerol lipase (MAGL) showed that the expression of this enzyme correlated with tumor aggressiveness and invasive phenotype. MAGL was acting through the release of free fatty acids, and its knock down led to reduced invasiveness and tumor growth. Interestingly, the exogenous addition of saturated fatty acids restored the migration ability of cells in which MAGL was inhibited. ${ }^{104}$ Besides the effects of high fat, high protein or diabetes, caloric restriction per se has been known to reduce cancer incidence. ${ }^{105}$ One possible explanation is that caloric restriction acts by altering insulin and IGF-1 levels, which work as growth factors for tumors. In this sense, a study on rodents demonstrated that these growth factors mediate the anti-tumoral effect of dietary restriction, and that constitutive activation of $\mathrm{PI} 3 \mathrm{~K}$ rendered the cancer cells resistant to diet restriction. This is the opposite of what would be expected taking into account that hyperactivation of PI3K promotes glycolysis and sensitivity to its inhibition. Clearly more studies need to be done in order to study whether caloric restriction or selective reduction of carbohydrates or fats is more effective, and whether the effects are due to metabolic changes or hormonal changes. Furthermore, most of the studies have been performed on laboratory rodents and need to be verified in humans. A combination of adapted diet (realistically applicable to humans) and chemotherapy might be an interesting approach to consider in the future. ${ }^{64,106}$

\section{Conclusions and Perspectives}

The field of cancer metabolism is progressing rapidly. Recent discoveries are prompting for a revision of biochemistry textbooks. In the XXI century the focus has moved from 'biochemical networks' to 'protein networks' to understand 
regulation of cell metabolism. ${ }^{107}$ However, we are still making relevant discoveries like the existence of an alternative glycolytic pathway. ${ }^{27}$ Besides the advance in basic knowledge, many questions remain as to whether metabolism represents the new cancer's Achilles' heel. We need to identify which specific oncogenic mutations confer sensitivity to inhibition of specific pathways (synthetic lethal interactions). This would allow stratification of patients in future clinical trials.

A myriad of metabolic enzymes and pathways are awaiting to be explored as targets for cancer therapy. In this regard, metabolism is probably the research area that would benefit the most from application of systems biology methodology to identify the key pathways. Additionally, metabolic profiling of samples from patients (Box 1) would offer relevant information

\section{Box 1}

\section{How to measure cancer metabolism}

Cell metabolism can be measured by metabolic profiling, which gives information of multiple pathways, or by measuring individual pathways and metabolites.

\section{Examples of methods to evaluate metabolism:}

- Glucose or amino acid uptake is measured by feeding cells with radioactive analogs of the desired compound and determining radioactivity in the cellular fraction.

- Glycolytic flux can be determined by measuring the conversion of $\left[5^{-}{ }^{3} \mathrm{H}\right]$ glucose to ${ }^{3} \mathrm{H}_{2} \mathrm{O}$ which diffuses into culture medium.

- Mitochondrial potential can be quantified by spectrophotometry or flow cytometry using fluorescent dyes such as tetramethylrhodamine ethylester (TMRE).

- ATP levels are measured by luminometry using the luciferase/ luciferin assay, supplied as a kit by several companies.

- Oxygen consumption can be measured by Clark electrodes.

- Lactate production can be measured by measurement of $\mathrm{pH}$ changes in culture medium.

- Instrumentation: An increasing number of companies are developing instrumentation for real time analysis of metabolic changes. Seahorse Biosciences for example commercializes instruments measuring oxygen consumption rate (which can be used to determine mitochondrial respiration using appropriate controls) and acidification rate of the extracellular media (glycolytic rate). On the other hand, Nova Biomedical Flex commercializes an automated measurement system of lactate, glucose, glutamine, ammonium from the medium in relation to cell density.

\section{Metabolic profiling:}

- MS (mass spectrometry). Various chromatographic techniques can be combined with mass spectrometry. GC-MS (Gas Chromatography) for example, allows the identification and quantification of a few hundred metabolites in single extracts. Since it has been used for a long time, protocols and data analysis are well set. GC-TOF-MS (Gas Chromatography Time-Of-Flight) brings a few advantages, notably reduced run time and mass accuracy. The last mass spectrometry technology used is LC-MS (Liquid Chromatography), which allows the analysis of a broader array of molecules. However, since it is a new method it needs to be carefully interpreted because less tables and protocols are available for comparison. Finally, another technique suitable with MS is ion mobility MS, which is particularly efficient for small molecules.

- NMR (nuclear magnetic resonance) spectrometry. Although NMR is less sensitive than MS, it is still used to evaluate metabolite composition of samples, being its main advantage that it is non invasive. In addition, NMR allows the determination of metabolite structure. that may be hindered in most studies by the nutrient enriched, high oxygen conditions in which cell lines are cultured. The role of autophagy in survival to metabolic targeting still requires clarification. Autophagy is a cellular response to starvation which is also engaged by cell damaging agents, including chemotherapy. ${ }^{108-110}$ Although autophagy is a survival response to many stimuli, in some contexts it promotes apoptotic or non-apoptotic cell death. ${ }^{111,112}$

Contradictory results exist in the literature regarding a protective or pro-death role of autophagy in response to energetic stress or ischemia (see for instance Altman et al.., ${ }^{113}$ Koike et al. ${ }^{114}$ and Russo et al. ${ }^{115}$ ).

Other interesting concepts that deserve more attention are the effects of metabolic changes on tumor stroma (and vice versa) and the role of redox metabolism and reactive oxygen species (ROS) in tumor progression. Production and removal of ROS is intimately linked to respiration and glucose and glutamine metabolism. ROS have a dual role in cancer, as signaling molecules that promote proliferation or as mediators of cell death induced by chemotherapy or ischemia. ${ }^{116-118}$ It is thus possible that some of the effects of metabolic reprogramming are due to regulation of ROS detoxification or synthesis. Lastly, we should keep in mind that cancer is not one disease, but hundreds of diseases, and for instance, metabolism of melanoma or liver tumor are as different as the shape or function of the tissues they originate from. Because of the intensive research effort in this new, yet very old, exciting field, major discoveries likely await in the near future.

\section{Conflict of Interest}

The authors declare no conflict of interest.

Acknowledgements. We wish to thank Stephen Tait, Javier Galindo, Alfredo Caro-Maldonado, Silvia Ramírez-Peinado and Dr Ludivine Pradelli, for suggestions, corrections and help with illustrations. We would also like to thank two anonymous reviewers for their input. We apologize for not mentioning relevant studies due to space constraints. This work was supported by grants to J-ER from the Association pour la Recherche sur le Cancer (ARC) and I'Agence Nationale de la Recherche (ANR-09-JCJC-0003-01) and to CM-P from the Association for International Cancer Research (AICR grant 08-0621) and the Fondo de Investigaciones Sanitarias-ISCIII from Spain (PI10/0104 and RTICC RD06/0020). JER is a recipient of a contrat d'interface INSERM-CHU de Nice.

1. Warburg O. On respiratory impairment in cancer cells. Science 1956; 124: 269

2. Jones RG, Thompson CB. Tumor suppressors and cell metabolism: a recipe for cancer growth. Genes Dev 2009; 23: 537-548.

3. DeBerardinis RJ, Sayed N, Ditsworth D, Thompson CB. Brick by brick: metabolism and tumor cell growth. Curr Opin Genetics Dev 2008; 18: 54.

4. Michalek RD, Rathmell JC. The metabolic life and times of a T-cell. Immunological Reviews 2010; 236: 190.

5. Fritz V, Fajas L. Metabolism and proliferation share common regulatory pathways in cancer cells. Oncogene 2010; 29: 4369-4377.

6. Alberola-lla J, Hernandez-Hoyos G. The Ras/MAPK cascade and the control of positive selection. Immunol Rev 2003; 191: 79-96.

7. Ramjaun AR, Downward J. Ras and phosphoinositide 3-kinase: partners in development and tumorigenesis. Cell Cycle 2007; 6: 2902-2905.

8. Ahmad I, Patel R, Liu Y, Singh LB, Taketo MM, Wu XR et al. Ras mutation cooperates with beta-catenin activation to drive bladder tumourigenesis. Cell Death Dis 2011; 2: e124.

9. Barthel A, Okino ST, Liao J, Nakatani K, Li J, Whitlock Jr JP et al. Regulation of GLUT1 gene transcription by the serine/threonine kinase Akt1. J Biol Chem 1999; 274: 20281-20286.

10. Robey RB, Hay N. Mitochondrial hexokinases, novel mediators of the antiapoptotic effects of growth factors and Akt. Oncogene 2006; 25: 4683-4696. 
11. Rathmell JC, Fox CJ, Plas DR, Hammerman PS, Cinalli RM, Thompson CB. Akt-Directed Glucose Metabolism Can Prevent Bax Conformation Change and Promote Growth Factor-Independent Survival. Mol Cell Biol 2003; 23: 7315-7328.

12. Gottlob K, Majewski N, Kennedy S, Kandel E, Robey RB, Hay N. Inhibition of early apoptotic events by Akt/PKB is dependent on the first committed step of glycolysis and mitochondrial hexokinase. Genes Dev 2001; 15: 1406-1418.

13. Düvel K, Yecies JL, Menon S, Raman P, Lipovsky Al, Souza AL et al. Activation of a Metabolic Gene Regulatory Network Downstream of mTOR Complex 1. Molecular Cell 2010; 39: 171 .

14. Krycer JR, Sharpe LJ, Luu W, Brown AJ. The Akt-SREBP nexus: cell signaling meets lipid metabolism. Trends Endocrinol Metab 2010; 21: 268-276.

15. Yang YA, Han WF, Morin PJ, Chrest FJ, Pizer ES. Activation of fatty acid synthesis during neoplastic transformation: role of mitogen-activated protein kinase and phosphatidylinositol 3-kinase. Exp Cell Res 2002; 279: 80-90.

16. Wise DR, DeBerardinis RJ, Mancuso A, Sayed N, Zhang XY, Pfeiffer HK et al. Myc regulates a transcriptional program that stimulates mitochondrial glutaminolysis and leads to glutamine addiction. Proc Natl Acad Sci USA 2008; 105: 18782-18787.

17. Gao P, Tchernyshyov I, Chang T-C, Lee Y-S, Kita K, Ochi T et al. c-Myc suppression of $\mathrm{miR}-23 \mathrm{a} / \mathrm{b}$ enhances mitochondrial glutaminase expression and glutamine metabolism. Nature 2009; 458: 762.

18. Dang CV, Le A, Gao P. MYC-induced cancer cell energy metabolism and therapeutic opportunities. Clin Cancer Res 2009; 15: 6479-6483.

19. Hu S, Balakrishnan A, Bok RA, Anderton B, Larson PEZ, Nelson SJ et al. 13C-Pyruvate imaging reveals alterations in glycolysis that precede c-Myc-induced tumor formation and regression. Cell Metabolism 2011; 14: 131-142.

20. David CJ, Chen M, Assanah M, Canoll P, Manley JL. HnRNP proteins controlled by c-Myc deregulate pyruvate kinase mRNA splicing in cancer. Nature 2010; 463 364-368.

21. Lv L, Li D, Zhao D, Lin R, Chu Y, Zhang $\mathrm{H}$ et al. Acetylation targets the M2 isoform of pyruvate kinase for degradation through chaperone-mediated autophagy and promotes tumor growth. Molecular Cell 2011; 42: 719-730.

22. Christofk HR, Vander Heiden MG, Wu N, Asara JM, Cantley LC. Pyruvate kinase M2 is a phosphotyrosine-binding protein. Nature 2008; 452: 181-186.

23. Christofk HR, Vander Heiden MG, Harris MH, Ramanathan A, Gerszten RE, Wei R et al. The M2 splice isoform of pyruvate kinase is important for cancer metabolism and tumou growth. Nature 2008; 452: 230-233.

24. Hitosugi T, Kang S, Vander Heiden MG, Chung TW, Elf S, Lythgoe $\mathrm{K}$ et al. Tyrosine phosphorylation inhibits PKM2 to promote the Warburg effect and tumor growth. Sci Signal 2009; 2: ra73

25. Sun $Q$, Chen X, Ma J, Peng $H$, Wang $F$, Zha X et al. Mammalian target of rapamycin upregulation of pyruvate kinase isoenzyme type $\mathrm{M} 2$ is critical for aerobic glycolysis and tumor growth. Proc Natl Acad Sci USA 2011; 108: 4129-4134.

26. Luo W, Hu H, Chang R, Zhong J, Knabel M, O'meally R et al. Pyruvate Kinase M2 Is a PHD3-Stimulated Coactivator for Hypoxia-Inducible Factor 1. Cell 2011; 145: 732-744.

27. Vander Heiden MG, Locasale JW, Swanson KD, Sharfi H, Heffron GJ, Amador-Noguez D et al. Evidence for an Alternative Glycolytic Pathway in Rapidly Proliferating Cells. Science 2010; 329: 1492-1499.

28. Semenza GL. Defining the role of hypoxia-inducible factor 1 in cancer biology and therapeutics. Oncogene 2010; 29: 625-634.

29. Guccini I, Serio D, Condo I, Rufini A, Tomassini B, Mangiola A et al. Frataxin participates to the hypoxia-induced response in tumors. Cell Death Dis 2011; 2: e123.

30. Michelakis ED, Sutendra G, Dromparis P, Webster L, Haromy A, Niven E et al. Metabolic modulation of glioblastoma with dichloroacetate. Sci Transl Med 2010; 2: 31ra34.

31. Spruijt L, Naviaux RK, McGowan KA, Nyhan WL, Sheean G, Haas RH et al. Nerve conduction changes in patients with mitochondrial diseases treated with dichloroacetate. Muscle Nerve 2001; 24: 916-924.

32. Stacpoole PW, Henderson GN, Yan Z, James MO. Clinical pharmacology and toxicology of dichloroacetate. Environ Health Perspect 1998; 106 (Suppl 4): 989-994.

33. Cairns RA, Harris IS, Mak TW. Regulation of cancer cell metabolism. Nat Rev Cancer 2011; 11: 85-95.

34. Kroemer G, Pouyssegur J. Tumor cell metabolism: cancer's Achilles' Heel. Cancer Cell 2008; 13: 472

35. Sermeus A, Michiels $C$. Reciprocal influence of the p53 and the hypoxic pathways. Cell Death Dis 2011; 2: e164.

36. Koster R, Timmer-Bosscha H, Bischoff R, Gietema JA, de Jong S. Disruption of the MDM2-p53 interaction strongly potentiates p53-dependent apoptosis in cisplatin-resistan human testicular carcinoma cells via the Fas/FasL pathway. Cell Death Dis 2011; 2: e148.

37. Bensaad K, Tsuruta A, Selak MA, Vidal MN, Nakano K, Bartrons $R$ et al. TIGAR, a p53-inducible regulator of glycolysis and apoptosis. Cell 2006; 126: 107-120.

38. Matoba S, Kang J-G, Patino WD, Wragg A, Boehm M, Gavrilova $O$ et al. p53 Regulates Mitochondrial Respiration. Science 2006; 312: 1650-1653.

39. Hu W, Zhang $C$, Wu R, Sun Y, Levine A, Feng Z. Glutaminase 2, a novel p53 target gene regulating energy metabolism and antioxidant function. Proc Natl Acad Sci USA 2010; 107: $7455-7460$

40. Suzuki S, Tanaka T, Poyurovsky MV, Nagano H, Mayama T, Ohkubo S et al. Phosphateactivated glutaminase (GLS2), a p53-inducible regulator of glutamine metabolism and reactive oxygen species. Proc Natl Acad Sci USA 2010; 107: 7461-7466.
41. Zhao Y, Coloff JL, Ferguson EC, Jacobs SR, Cui K, Rathmell JC. Glucose metabolism attenuates p53 and puma-dependent cell death upon growth factor deprivation. J Biol Chem 2008; 283: 36344-36353.

42. Jones RG, Plas DR, Kubek S, Buzzai M, Mu J, Xu Y et al. AMP-activated protein kinase induces a p53-dependent metabolic checkpoint. Molecular Cell 2005; 18: 283.

43. Shaw RJ, Kosmatka M, Bardeesy N, Hurley RL, Witters LA, DePinho RA et al. The tumo suppressor LKB1 kinase directly activates AMP-activated kinase and regulates apoptosis in response to energy stress. Proc Natl Acad Sci USA 2004; 101: 3329-3335.

44. Choo AY, Kim SG, Vander Heiden MG, Mahoney SJ, Vu H, Yoon S-O et al. Glucose addiction of TSC null cells is caused by failed mTORC1-dependent balancing of metabolic demand with supply. Molecular Cell 2010; 38: 487.

45. Frezza $C$, Zheng $L$, Folger $O$, Rajagopalan KN, MacKenzie ED, Jerby $L$ et al. Haem oxygenase is synthetically lethal with the tumour suppressor fumarate hydratase. Nature 2011; 477: 225-228.

46. Swietach $\mathrm{P}$, Vaughan-Jones RD, Harris AL. Regulation of tumor $\mathrm{pH}$ and the role of carbonic anhydrase 9. Cancer Metastasis Rev 2007; 26: 299-310.

47. Fischer K, Hoffmann P, Voelkl S, Meidenbauer N, Ammer J, Edinger M et al. Inhibitory effect of tumor cell-derived lactic acid on human T cells. Blood 2007; 109: 3812-3819.

48. Parsons DW, Jones S, Zhang X, Lin JC, Leary RJ, Angenendt $P$ et al. An integrated genomic analysis of human glioblastoma multiforme. Science 2008; 321: 1807-1812.

49. Yan H, Parsons DW, Jin G, McLendon R, Rasheed BA, Yuan W et al. IDH1 and IDH2 mutations in gliomas. N Engl J Med 2009; 360: 765-773.

50. Dang L, White DW, Gross S, Bennett BD, Bittinger MA, Driggers EM et al. Cancerassociated IDH1 mutations produce 2-hydroxyglutarate. Nature 2009; 462: 739-744.

51. Ward PS, Patel J, Wise DR, Abdel-Wahab O, Bennett BD, Coller HA et al. The common feature of leukemia-associated IDH1 and IDH2 mutations is a neomorphic enzyme activity converting alpha-ketoglutarate to 2-hydroxyglutarate. Cancer Cell 2010; 17: 225-234.

52. Xu W, Yang H, Liu Y, Yang Y, Wang P, Kim SH et al. Oncometabolite 2-hydroxyglutarate is a competitive inhibitor of alpha-ketoglutarate-dependent dioxygenases. Cancer Cell 2011; 19: 17-30.

53. Figueroa ME, Abdel-Wahab O, Lu C, Ward PS, Patel J, Shih A et al. Leukemic IDH1 and IDH2 mutations result in a hypermethylation phenotype, disrupt TET2 function, and impair hematopoietic differentiation. Cancer Cell 2011; 18: 553-567.

54. Zhao S, Lin Y, Xu W, Jiang W, Zha Z, Wang P et al. Glioma-derived mutations in IDH1 dominantly inhibit IDH1 catalytic activity and induce HIF-1alpha. Science 2009; 324: 261-265.

55. Chowdhury R, Yeoh KK, Tian YM, Hillringhaus L, Bagg EA, Rose NR et al. The oncometabolite 2-hydroxyglutarate inhibits histone lysine demethylases. EMBO Rep 2011; 12: 463-469.

56. Yen KE, Bittinger MA, Su SM, Fantin VR. Cancer-associated IDH mutations: biomarker and therapeutic opportunities. Oncogene 2010; 29: 6409-6417.

57. Maurer U, Charvet C, Wagman AS, Dejardin E, Green DR. Glycogen synthase kinase-3 regulates mitochondrial outer membrane permeabilization and apoptosis by destabilization of MCL-1. Mol Cell 2006; 21: 749-760.

58. Zhao Y, Altman BJ, Coloff JL, Herman CE, Jacobs SR, Wieman HL et al. Glycogen Synthase Kinase 3\{alpha\} and 3\{beta\} Mediate a Glucose-Sensitive Antiapoptotic Signaling Pathway To Stabilize Mcl-1. Mol Cell Biol 2007; 27: 4328-4339.

59. Pradelli LA, Beneteau M, Chauvin C, Jacquin MA, Marchetti S, Munoz-Pinedo $C$ et al. Glycolysis inhibition sensitizes tumor cells to death receptors-induced apoptosis by AMP kinase activation leading to Mcl-1 block in translation. Oncogene 2010; 29: 1641.

60. Coloff JL, Macintyre AN, Nichols AG, Liu T, Gallo CA, Plas DR et al. Akt-Dependent glucose metabolism promotes Mcl-1 synthesis to maintain cell survival and resistance to Bcl-2 inhibition. Cancer Res 2011; 71: 5204-5213.

61. Esposti MD. Bcl-2 antagonists and cancer: from the clinic, back to the bench. Cell Death Dis 2010; 1: e37.

62. Pujals A, Renouf B, Robert A, Chelouah S, Hollville E, Wiels J. Treatment with a BH3 mimetic overcomes the resistance of latency III EBV (+) cells to p53-mediated apoptosis. Cell Death Dis 2011; 2: e184.

63. Placzek WJ, Wei J, Kitada S, Zhai D, Reed JC, Pellecchia M. A survey of the antiapoptotic $\mathrm{Bcl}-2$ subfamily expression in cancer types provides a platform to predict the efficacy of Bcl-2 antagonists in cancer therapy. Cell Death Dis 2010; 1: e40.

64. El Mjiyad N, Caro-Maldonado A, Ramirez-Peinado S, Munoz-Pinedo C. Sugar-free approaches to cancer cell killing. Oncogene 2011; 30: 253-264.

65. Lowman XH, McDonnell MA, Kosloske A, Odumade OA, Jenness C, Karim CB et al. The proapoptotic function of Noxa in human leukemia cells is regulated by the kinase Cdk5 and by glucose. Mol Cell 2010; 40: 823-833.

66. Danial NN, Gramm CF, Scorrano L, Zhang C-Y, Krauss S, Ranger AM et al. BAD and glucokinase reside in a mitochondrial complex that integrates glycolysis and apoptosis. Nature 2003; 424: 952

67. Munoz-Pinedo C, Ruiz-Ruiz C, Ruiz de Almodovar C, Palacios C, Lopez-Rivas A. Inhibition of glucose metabolism sensitizes tumor cells to death receptor-triggered apoptosis through enhancement of death-inducing signaling complex formation and apical procaspase-8 processing. J Biol Chem 2003; 278: 12759-12768.

68. Colell A, Ricci JE, Tait S, Milasta S, Maurer U, Bouchier-Hayes L et al. GAPDH and autophagy preserve survival after apoptotic cytochrome $c$ release in the absence of caspase activation. Cell 2007; 129: 983-997. 
69. Ferraro E, Pulicati A, Cencioni MT, Cozzolino M, Navoni F, di Martino S et al. Apoptosome-deficient cells lose cytochrome $c$ through proteasomal degradation but survive by autophagy-dependent glycolysis. Mol. Biol. Cell 2008; 19: 3576-3588.

70. Ricci JE, Munoz-Pinedo C, Fitzgerald P, Bailly-Maitre B, Perkins GA, Yadava N et al. Disruption of mitochondrial function during apoptosis is mediated by caspase cleavage of the p75 subunit of complex I of the electron transport chain. Cell 2004; 117: 773-786.

71. Pathania D, Millard M, Neamati N. Opportunities in discovery and delivery of anticancer drugs targeting mitochondria and cancer cell metabolism. Adv Drug Deliv Rev 2009; 61: 1250-1275.

72. Tennant DA, Duran RV, Gottlieb E. Targeting metabolic transformation for cancer therapy. Nat Rev Cancer 2010; 10: 267.

73. Marino ML, Fais S, Djavaheri-Mergny M, Villa A, Meschini S, Lozupone F et al. Proton pump inhibition induces autophagy as a survival mechanism following oxidative stress in human melanoma cells. Cell Death Dis 2010; 1: e87.

74. Caro-Maldonado A, Munoz-Pinedo C. Dying for something to eat: how cells respond to starvation. The Open Cell Signaling Journal 2011; 3: 42-51.

75. Ramírez-Peinado S, Alcázar-Limones F, Lagares-Tena L, El Mjiyad N, Caro-Maldonado A, Tirado $\mathrm{OM}$ et al. 2-deoxyglucose induces Noxa-dependent apoptosis in alveolar rhabdomyosarcoma. Cancer Res 2011; 71: 6796-6806.

76. Eagle H. Nutrition needs of mammalian cells in tissue culture. Science 1955; 122: $501-514$.

77. Nicklin $\mathrm{P}$, Bergman $\mathrm{P}$, Zhang B, Triantafellow E, Wang $\mathrm{H}$, Nyfeler B et al. Bidirectional transport of amino acids regulates mTOR and autophagy. Cell 2009; 136: 521-534.

78. DeBerardinis RJ, Mancuso A, Daikhin E, Nissim I, Yudkoff M, Wehrli $S$ et al Beyond aerobic glycolysis: Transformed cells can engage in glutamine metabolism that exceeds the requirement for protein and nucleotide synthesis. Proceedings of the National Academy of Sciences 2007; 104: 19345-19350.

79. Wise DR, Thompson CB. Glutamine addiction: a new therapeutic target in cancer. Trends Biochem Sci 2010; 35: 427-433.

80. Avramis VI, Panosyan EH. Pharmacokinetic/pharmacodynamic relationships of asparaginase formulations: the past, the present and recommendations for the future. Clin Pharmacokinet 2005; 44: 367-393.

81. Lessner HE, Valenstein S, Kaplan R, DeSimone P, Yunis A. Phase II study of L-asparaginase in the treatment of pancreatic carcinoma. Cancer Treat Rep 1980; 64 : $1359-1361$.

82. Possemato R, Marks KM, Shaul YD, Pacold ME, Kim D, Birsoy K et al. Functional genomics reveal that the serine synthesis pathway is essential in breast cancer. Nature 2011

83. Locasale JW, Grassian AR, Melman T, Lyssiotis CA, Mattaini KR, Bass AJ et al. Phosphoglycerate dehydrogenase diverts glycolytic flux and contributes to oncogenesis. Nat Genet 2011; 43: 869-874.

84. Yuneva M, Zamboni N, Oefner P, Sachidanandam R, Lazebnik Y. Deficiency in glutamine but not glucose induces MYC-dependent apoptosis in human cells. J Cell Biol 2007; 178 93-105

85. Wensveen F, Alves N, Derks I, Reedquist K, Eldering E. Apoptosis induced by overall metabolic stress converges on the Bcl-2 family proteins Noxa and Mcl-1. Apoptosis 2011; 16: 708-721

86. Coleman PS. Membrane cholesterol and tumor bioenergetics. Ann NY Acad Sci 1986; 488: 451-467.

87. Hirsch HA, lliopoulos D, Joshi A, Zhang Y, Jaeger SA, Bulyk M et al. A transcriptional signature and common gene networks link cancer with lipid metabolism and diverse human diseases. Cancer Cell 2010; 17: 348-361

88. Li $\mathrm{Y}, \mathrm{He} \mathrm{K}$, Huang $\mathrm{Y}$, Zheng $\mathrm{D}$, Gao $\mathrm{C}$, Cui $\mathrm{L}$ et al. Betulin induces mitochondrial cytochrome $\mathrm{c}$ release associated apoptosis in human cancer cells. Mol Carcinog 2010; 49: $630-640$

89. Swinnen JV, Brusselmans K, Verhoeven G. Increased lipogenesis in cancer cells: new players, novel targets. Curr Opin Clin Nutr Metab Care 2006; 9: 358-365.

90. Hatzivassiliou G. ATP citrate lyase inhibition can suppress tumor cell growth. Cancer Cell 2005; 8: 311

91. Zaugg K, Yao Y, Reilly PT, Kannan K, Kiarash R, Mason J et al. Carnitine palmitoyltransferase $1 \mathrm{C}$ promotes cell survival and tumor growth under conditions of metabolic stress. Genes Dev 2011; 25: 1041-1051.

92. Brown AJ. Cholesterol, statins and cancer. Clin Exp Pharmacol Physiol 2007; 34: 135-141.

93. Huelsenbeck J, Henninger C, Schad A, Lackner KJ, Kaina B, Fritz G. Inhibition of Rac signaling by lovastatin protects against anthracycline-induced cardiac toxicity. Cell Death Dis 2011; 2: e190.

94. Donadelli M, Dando I, Zaniboni T, Costanzo C, Dalla Pozza E, Scupoli MT et al. Gemcitabine/cannabinoid combination triggers autophagy in pancreatic cancer cells through a ROS-mediated mechanism. Cell Death Dis 2011; 2: e152.

95. Garg D, Henrich S, Salo-Ahen OMH, Myllykallio H, Costi MP, Wade RC. Nove Approaches for Targeting Thymidylate Synthase To Overcome the Resistance and Toxicity of Anticancer Drugs. Journal of Medicinal Chemistry 2010; 53: 6539.

96. Blagosklonny MV. Linking calorie restriction to longevity through sirtuins and autophagy: any role for TOR. Cell Death Dis 2010; 1: e12.

97. Morselli E, Maiuri MC, Markaki M, Megalou E, Pasparaki A, Palikaras K et al. Caloric restriction and resveratrol promote longevity through the Sirtuin-1-dependent induction of autophagy. Cell Death Dis 2010; 1: e10.

98. Willcox DC, Willcox BJ, Todoriki H, Suzuki M. The Okinawan diet: health implications of a low-calorie, nutrient-dense, antioxidant-rich dietary pattern low in glycemic load. J Am Coll Nutr 2009; 28 (Suppl): 500S-516S.

99. Ho VW, Leung K, Hsu A, Luk B, Lai J, Shen SY et al. A low carbohydrate, high protein diet slows tumor growth and prevents cancer initiation. Cancer Res 2011; 71 4484-4493.

100. Bowker SL, Majumdar SR, Veugelers P, Johnson JA. Increased cancer-related mortality for patients with type 2 diabetes who use sulfonylureas or insulin. Diabetes Care 2006; 29. 254-258.

101. Evans JM, Donnelly LA, Emslie-Smith AM, Alessi DR, Morris AD. Metformin and reduced risk of cancer in diabetic patients. Bmj 2005; 330: 1304-1305

102. Tomic T, Botton T, Cerezo M, Robert G, Luciano F, Puissant A et al. Metformin inhibits melanoma development through autophagy and apoptosis mechanisms. Cell Death Dis 2011; 2: e199.

103. Venkateswaran V, Klotz LH. Diet and prostate cancer: mechanisms of action and implications for chemoprevention. Nat Rev Urol 2010; 7: 442-453.

104. Nomura DK, Long JZ, Niessen S, Hoover HS, Ng SW, Cravatt BF. Monoacylglycero lipase regulates a fatty acid network that promotes cancer pathogenesis. Cell 2010; 140 49-61.

105. Hursting SD, Lavigne JA, Berrigan D, Perkins SN, Barrett JC. Calorie restriction, aging, and cancer prevention: mechanisms of action and applicability to humans. Annu Rev Med 2003; 54: 131-152.

106. Lee $\mathrm{C}$, Longo VD. Fasting vs dietary restriction in cellular protection and cancer treatment: from model organisms to patients. Oncogene 2011; 30: 3305-3316

107. Metallo CM, Vander Heiden MG. Metabolism strikes back: metabolic flux regulates cell signaling. Genes Dev 2010; 24: 2717-2722.

108. Knight RA, Melino G. Cell death in disease: from 2010 onwards. Cell Death Dis 2011; 2: e202.

109. Ling LU, Tan KB, Lin H, Chiu GN. The role of reactive oxygen species and autophagy in safingol-induced cell death. Cell Death Dis 2011; 2: e129.

110. Heidari N, Hicks MA, Harada H. GX15-070 (obatoclax) overcomes glucocorticoid resistance in acute lymphoblastic leukemia through induction of apoptosis and autophagy. Cell Death Dis 2010; 1: e76.

111. Elgendy M, Sheridan C, Brumatti G, Martin SJ. Oncogenic Ras-induced expression of Noxa and Beclin-1 promotes autophagic cell death and limits clonogenic survival. Mol Cell 2011; 42: 23-35.

112. Kuwahara $Y$, Oikawa T, Ochiai $Y$, Roudkenar MH, Fukumoto M, Shimura T et al. Enhancement of autophagy is a potential modality for tumors refractory to radiotherapy. Cell Death Dis 2011; 2: e177.

113. Altman BJ, Wofford JA, Zhao Y, Coloff JL, Ferguson EC, Wieman HL et al Autophagy Provides Nutrients but Can Lead to Chop-dependent Induction of Bim to Sensitize Growth Factor-deprived Cells to Apoptosis. Mol. Biol. Cell 2009; 20 $1180-1191$

114. Koike M, Shibata M, Tadakoshi M, Gotoh K, Komatsu M, Waguri S et al. Inhibition of autophagy prevents hippocampal pyramidal neuron death after hypoxic-ischemic injury. Am J Pathol 2008; 172: 454-469.

115. Russo R, Berliocchi L, Adornetto A, Varano GP, Cavaliere F, Nucci $C$ et al. Calpainmediated cleavage of Beclin-1 and autophagy deregulation following retinal ischemic injury in vivo. Cell Death Dis 2011; 2: e144.

116. Sarsour EH, Kumar MG, Chaudhuri L, Kalen AL, Goswami PC. Redox control of the cell cycle in health and disease. Antioxid Redox Signal 2009; 11: 2985-3011.

117. Coriat R, Marut W, Leconte M, Ba LB, Vienne A, Chereau C et al. The organotelluride catalyst LAB027 prevents colon cancer growth in the mice. Cell Death Dis 2011; 2: e191.

118. Thomas E, Zeps N, Rigby P, Hartmann P. Reactive oxygen species initiate luminal but not basal cell death in cultured human mammary alveolar structures: a potential regulator of involution. Cell Death Dis 2011; 2: e189.

119. Puzio-Kuter AM. The Role of p53 in Metabolic Regulation. Genes Cancer 2011 2: $385-391$.

120. Caro-Maldonado A, Tait SWG, Ramirez-Peinado S, Ricci JE, Fabregat I, Green DR et al. Glucose deprivation induces an atypical form of apoptosis mediated by caspase-8 in Bax-, Bak-deficient cells. Cell Death Differ 2010; 17: 1335-1344.
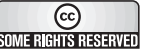

Cell Death and Disease is an open-access journal published by Nature Publishing Group. This work is licensed under the Creative Commons Attribution-Noncommercial-No Derivative Works 3.0 Unported License. To view a copy of this license, visit http://creativecommons.org/licenses/by-nc-nd/3.0/ 